\title{
Emergency surgery after failed device closure of the atrial septal defect
}

\author{
Igor E. Konstantinov, MD, PhD, Pankaj Saxena, MCh, DNB, Lisa Friederich, MBBS, and Mark A. J. Newman, FRACS,
} Perth, Australia

$\mathrm{F}$ rom November 1999 to November 2005, 83 patients underwent transcatheter device closure of the secundum atrial septal defect (ASD) at our institution. Four (4.8\%) patients urgently required surgery following the failed placement of the devices.

\section{Clinical Summaries}

PATIENT 1. A 66-year-old woman with chronic atrial fibrillation (AF) and transient ischemic attacks (TIA) underwent closure of a 5-mm ASD with 14-mm Amplatzer device (AGA Medical Corp, Golden Valley, Minn). However, she remained symptomatic, with residual left-to-right shunt. A 25-mm Amplatzer device was placed 6 months later. The devices partially dehisced 2 years later, with large left-to-right shunt with pulmonary artery (PA) systolic pressure of $62 \mathrm{~mm} \mathrm{Hg}$. An attempt to place a 35-mm Amplatzer device resulted in further dehiscence of the interlocked devices, with threatening embolization. The patient underwent urgent surgery. Atrial septum was exposed through midline sternotomy. The devices were dehisced from the entire posterior rim of the septum and displaced into the left atrium (LA; Figure 1). The devices were retrieved from the LA, and the ASD was closed with direct suture. Aortic crossclamp (ACC) time was 30 minutes. Cardiopulmonary bypass (CPB) time was 57 minutes. The patient was discharged home on postoperative day 8 . She died 30 months later from interstitial lung disease presumably related to amiodarone therapy for chronic AF.

PATIENT 2. A 38-year old woman developed syncopal episodes. A sick sinus syndrome was diagnosed, and a permanent pacemaker was required. The echocardiogram demonstrated a 16-mm-diameter ASD. An attempt to place an 18-mm Amplatzer device resulted in the rupture of the inferior rim of the atrial septum. An attempt to place a 36-mm Amplatzer device resulted in further rupture and an insufficient inferior rim to secure the device. The ASD size increased to $2.5 \mathrm{~cm} \times 4 \mathrm{~cm}$. A large flail segment of the inferior rim raised the concern of embolization. Emergency surgery was performed through midline sternotomy. The flail segment of the atrial septum was excised, and the ASD was closed

\footnotetext{
From the Department of Cardiothoracic Surgery, Sir Charles Gairdner Hospital, Perth, WA, Australia.

Received for publication Dec 2, 2006; revisions received Dec 14, 2006; accepted for publication Jan 5, 2007.

Address for reprints: Igor E. Konstantinov, Department of Cardiothoracic Surgery, Sir Charles Gairdner Hospital, Perth, WA, Australia (E-mail: igorkonst@hotmail.com).

J Thorac Cardiovasc Surg 2007;133:1370-1

$0022-5223 / \$ 32.00$

Copyright @ 2007 by The American Association for Thoracic Surgery doi:10.1016/j.jtcvs.2007.01.004
}

with an autologous pericardial patch. ACC time was 21 minutes. CPB was 37 minutes. She was discharged on postoperative day 5 and underwent pacemaker insertion for the sick sinus syndrome. The patient remains asymptomatic at 1-year follow-up.

PATIENT 3. A 61-year-old man with several episodes of TIA, hypertension, type 2 diabetes, and 10-mm ASD with left-to-right shunt underwent ASD closure with a 35-mm Helex occluder device (W.L. Gore and Associates, Inc, Flagstaff, Ariz). Upon deployment of the device, the patient developed cardiac tamponade. A pigtail catheter was placed in the pericardial cavity, and continuous autotransfusion of the aspirated blood was performed. Emergency surgery was performed through midline sternotomy. A tear of the atrial septum extending into the left atrial wall was found. The tear and the ASD were closed by direct running suture. ACC was 18 minutes. CPB was 29 minutes. The patient was discharged home on day 5 . He remains asymptomatic at 3-year follow-up.

PATIENT 4. A 16-year-old asymptomatic woman was considered for device closure of an 18-mm-diameter ASD with shunt of 2:1 and normal PA pressures. An attempt to place a 26-mm Amplatzer device resulted in the tear of the inferior rim of the atrial septum. The device was removed, and a 28-mm Amplatzer device was placed. The second device, however, embolized entirely into the LA, and the patient underwent urgent surgical removal of the device. The device was retrieved from the LA through midline sternotomy with standard CPB. A long tear was found in the inferior rim of the ASD, which measured $1.8 \mathrm{~cm} \times 4$ $\mathrm{cm}$. The ASD was closed with direct suture. ACC time was 18

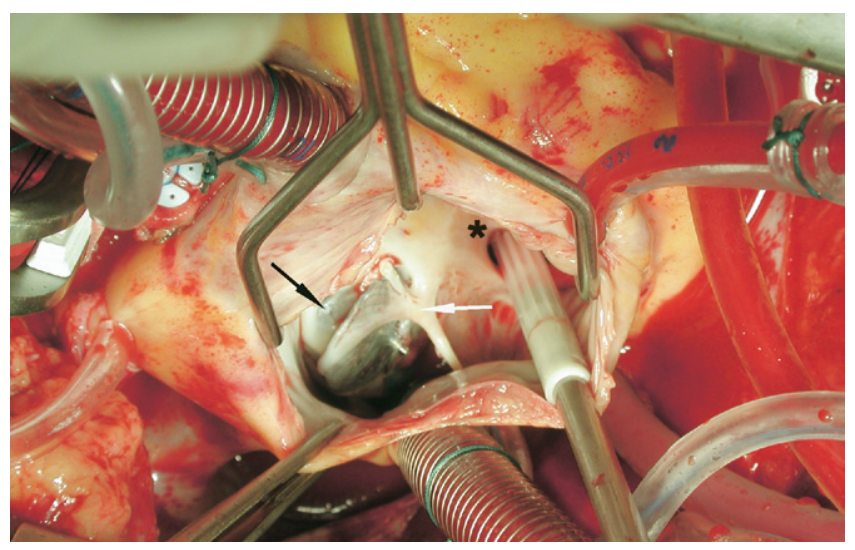

Figure 1. Intraoperative view of the large ASD and dehisced occluder devices. The interlocked Amplatzer device is identified with a black arrow. A thin membranous inferior rim of the ASD is identified with a white arrow. Coronary sinus is marked with an asterisk. 
minutes. CPB time was 30 minutes. The patient was discharged on postoperative day 6 . She was doing well at 7-year follow up.

\section{Discussion \\ The long-term results of surgical ASD repair are excellent. The long-term results of all therapeutic percutaneous interventions, including ASD closure, must be compared with the gold standards set by surgery. Early and late complications of the device closure of the ASD have been reported. ${ }^{1-5}$ Although the transcatheter ASD closure is useful in selected patients, it can be associated with life-threatening complications, including cardiac tamponade, de- vice erosion into aorta with aorto-to-atrium fistula formation, and systemic or pulmonary embolization. ${ }^{1-5}$ The patients must be informed of the current results of interventional and surgical approaches and make an informed decision after talking to both interventional cardiologist and cardiothoracic surgeon.}

\section{References}

1. Contrafouris CA, Chatzis AC, Giannopoulos NM, et al. Emergency surgical intervention for runaway atrial septal defect closure devices: a word of caution. J Thorac Cardiovasc Surg. 2006;132:1234-5.

2. Chessa M, Carminatti M, Butera G, Binni RM, Drago M, Rosti L, et al. Early and late complications associated with transcatheter occlusion of atrial septal defects. J Am Coll Cardiol. 2002;39:1061-5.

3. Mello DM, Fahey J, Kopf GS. Repair of aortic-left atrial fistula following the transcatheter closure of an atrial septal defect. Ann Thorac Surg. 2005;80:1495-8.

4. Knirscgh W, Dodge-Khatami A, Balmer C, Peuster M, Kadner A, Weiss M, et al. Aortic sinus-left atrial fistula after interventional closure of atrial septal defect. Catheter Cardiovasc Interv. 2005;66: 10-7.

5. Grayburn PA, Schwartz B, Anwar A, Hebeler RF. Migration of an Amplatzer septal occluder device for closure of atrial septal defect into the ascending aorta with formation of an aorta-to-right atrial fistula. Am J Cardiol. 2005;96:1607-9.

\section{Reversal of increased pulmonary arterial pressure associated with systemic venous collaterals after tonsillectomy in a Fontan candidate after the Glenn procedure: Impact of obstructive sleep apnea on Fontan circulation}

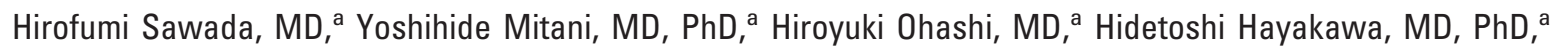

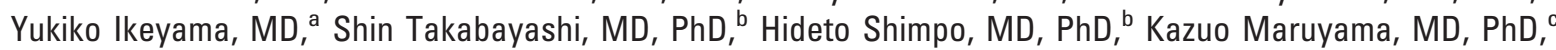
and Yoshihiro Komada, MD, PhD, ${ }^{a}$ Mie, Japan

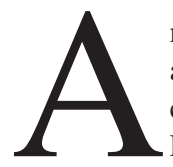

$\mathrm{n}$ increase in pulmonary artery (PA) pressure, associated with the development of systemic venous collaterals, is one of the greatest risks for candidates for the Fontan procedure after the Glenn procedure. ${ }^{1,2} \mathrm{Sim}-$ ple coil embolization for such collaterals may not be sufficient, inducing other collaterals accompanied by persistent high PA pressure with poor outcomes. Mild pulmonary hypertension is a common complication associated with obstructive sleep apnea (OSA). ${ }^{3}$ However, the effects of OSA on pulmonary circulation in Fontan candidates are unknown. We report a patient with a successful Fontan completion in whom high PA pressure associated

From the Departments of Pediatrics, ${ }^{a}$ Thoracic and Cardiovascular Surgery, ${ }^{\mathrm{b}}$ and Anesthesiology, ${ }^{\mathrm{c}}$ Mie University Graduate School of Medicine, Tsu, Mie, Japan.

Received for publication Dec 27, 2006; accepted for publication Jan 2, 2007.

Address for reprints: Yoshihide Mitani, MD, PhD, Department of Pediatrics, Mie University Graduate School of Medicine, 2-174 Edobashi, Tsu city, Mie Pref, 514-8507, Japan (E-mail: ymitani@clin.medic.mie-u.ac.jp).

J Thorac Cardiovasc Surg 2007;133:1371-3

$0022-5223 / \$ 32.00$

Copyright $\odot 2007$ by The American Association for Thoracic Surgery doi:10.1016/j.jtcvs.2007.01.016 with venous collaterals after the Glenn procedure was reversed after a tonsillectomy for OSA after coil embolization.

\section{Clinical Summary}

A 3-year-old boy with pulmonary atresia with an intact ventricular septum presented with progressive cyanosis. The boy had undergone a right modified Blalock-Taussig shunting procedure in the neonatal period and a bidirectional cavopulmonary anastomosis at the age of 6 months. His parents had noticed his dysphagia and nocturnal apnea accompanied by snoring since he was 1 year and 6 months old. Cyanosis and desaturation increased at the age of 2 to 3 years (Figure 1). The patient was admitted to our hospital for the cardiac catheterization. The awake arterial oxygen saturation was $75 \%$. Contrast injection revealed systemic venous collaterals from the innominate vein to the left renal vein (Figure 2, A). The mean pressures in the PA and transpulmonary gradient, measured under controlled mechanical ventilation, were $15 \mathrm{~mm} \mathrm{Hg}$ and $11 \mathrm{~mm} \mathrm{Hg}$, respectively. At the age of 3 years and 6 months, transcatheter coil embolization for systemic venous collaterals was performed in this patient, and beraprost (an orally active prostacyclin analogue) was started. Cardiac catheterization 6 months after coil embolization revealed that the venous collaterals were completely occluded (Figure $2, B$ ) and the systemic saturation was $89 \%$. However, the mean PA pressure was as high as $17 \mathrm{~mm} \mathrm{Hg}$. Symptoms of OSA persisted, and third-degree hypertrophy of the tonsils was found. 